\title{
High prevalence of human immunodeficiency virus, hepatitis B and C viral infections among people who inject drugs: a potential stumbling block in the control of HIV and viral hepatitis in Tanzania
}

Rahim H. Kawambwa ${ }^{1 \dagger}$, Mtebe V. Majigo ${ }^{1 * \dagger}$ (D), Ahmed A. Mohamed ${ }^{2}$ and Mecky I. Matee ${ }^{1}$

\begin{abstract}
Background: Tanzania has witnessed a significant decrease in the prevalence of human immunodeficiency virus $(H I V)$ and viral hepatitis in the general population attributed to several interventional measures. It is uncertain whether this decline has also occurred among people who inject drugs (PWID). This study aimed to determine the seroprevalence of HIV, Hepatitis B and C viruses infection among PWID recruited from their hotspot sites in Dar es Salaam, Tanzania.

Methods: A cross-sectional study conducted between June and September 2017 recruited PWID from preidentified hotspot sites using a snowball referral sampling technique. A structured questionnaire was used to obtain information regarding socio-demographic characteristics, behaviour and drug use. Blood was tested for the presence of $\mathrm{IgG}$ antibodies against HIV and Hepatitis $\mathrm{C}$ virus (HCV) and hepatitis B surface antigen (HBsAg). Data were entered in the computer using excel software and analysed using Statistical Package for Social Sciences version 20.

Results: A total of 219 PWID were recruited, the majority of whom were males (74.9\%), unmarried (60.7\%), had low education (62.6\%) and low income (57.1\%). The median age was 39 years, with an inter-quartile range of 35-43. Approximately $32.0 \%$ had a history of drug injection for more than 3 years, $79.9 \%$ were injecting drugs more than 3 times per day and $47.5 \%$ were sharing needles. The overall prevalence of HIV, HBsAg, and HCV was 33.8, 7.8, and 50.2\%, respectively. There was serologic evidence of at least one infection for $68.9 \%$, while $22.4 \%$ had two or more infections. HIV infection was independently associated with being married, while HCV was associated with injecting drugs for more than 3 years and unprotected sex.

Conclusion: Over two-third of PWID had serologic evidence of infection with at least one virus while $22.4 \%$ having at least two infections. The high prevalence of HIV and viral hepatitis infections among PWID may hamper initiatives of ending HIV and viral hepatitis epidemics in Tanzania.
\end{abstract}

Keywords: PWID, HIV, Hepatitis B virus, Hepatitis C virus, Dar es Salaam, Tanzania

\footnotetext{
* Correspondence: mmajigo@gmail.com

${ }^{+}$Rahim H. Kawambwa and Mtebe V. Majigo contributed equally to this work.

'Department of Microbiology and Immunology, Muhimbili University of

Health and Allied Sciences, Dar es Salaam, Tanzania

Full list of author information is available at the end of the article
}

(c) The Author(s). 2020 Open Access This article is distributed under the terms of the Creative Commons Attribution 4.0 International License (http://creativecommons.org/licenses/by/4.0/), which permits unrestricted use, distribution, and reproduction in any medium, provided you give appropriate credit to the original author(s) and the source, provide a link to the Creative Commons license, and indicate if changes were made. The Creative Commons Public Domain Dedication waiver (http://creativecommons.org/publicdomain/zero/1.0/) applies to the data made available in this article, unless otherwise stated. 


\section{Background}

Tanzania has reported a steady fall in the prevalence of human immunodeficiency virus (HIV) infection in the general population, from $7 \%$ in 2004 [1] to $5.0 \%$ in 2017 [2]. The prevalence of hepatitis $B$ and $C$ viruses in the general and some sub-populations like health care workers, pregnant women and children have also been reported to decline $[3,4]$. These decline have been attributed to several preventive measures such as increasing awareness; screening blood donors; free condom distribution; prevention of mother to child transmission; expanded access to antiretroviral therapy; voluntary male circumcision; setting up HIV care and treatment clinic and methadone clinics [2]. It is unclear whether these preventive measures have had an effect on people who inject drugs (PWID) [5-8].

Injecting drug use (IDU) has been associated with increased risk of HIV, HBV, and HCV infections [9-12]. The prevalence of IDU vary greatly between countries, ranging from $0.02 \%$ to $5.21 \%$ [9]. A few studies conducted in Africa have reported IDU to be on the rise with potential significant contribution to the occurrence and spread of blood-borne infections [12-14].

In Tanzania, IDU has been reported since the 1990s [14]. Recognizing the scale of PWID, primarily the use of heroin [14] and high prevalence of HIV infection among them [1], a special outreach program was established in 2007, that offers a variety of preventive and supportive services including; education and communication materials, psychosocial support services and family group therapy meetings [15]. However, it is unclear as to whether these interventions, among several others taken by different stakeholders, have had an effect on the prevalence of the major blood-borne viral infections of public health importance. We conducted this study to provide the current status of seroprevalence of HIV, HBV and HCV infections among PWID in Dar es Salaam, recruited from their hotspot sites.

\section{Methods}

\section{Study design and setting}

This was a cross-sectional study conducted between June and September 2017 in Dar-es-salaam, the largest city in Tanzania with an estimated population of around 6 million inhabitants. Participants were recruited from pre-identified hotspot sites locally known as 'maskani' in Sinza, Kinondoni, Kimara, Tandale, Msasani, Mbagala, Kunduchi, Temeke, and Tandika suburbs of the City.

\section{Study population}

PWID aged 18 years or older, not enrolled in a methadone program, were eligible for inclusion into the study, while recruitment was subject to obtaining written consent. An individual had to admit having injected non- medically sanctioned psychotropic substances such as opioids, amphetamine-type stimulants, cocaine, hyposedatives, and hallucinogens either intravenously, intramuscularly or subcutaneously, during the past 30 days. The sample size was estimated to be 155 using Kish Leslie formula, and considering an $11.3 \%$ prevalence of HIV among PWID in Zanzibar [6] and a 5\% margin of error.

\section{Recruitment and data collection}

Participants were recruited following snowball chain referral sampling. First, we identified 30 PWID attending Muhimbili National Hospital (MNH) Methadone Clinic, who were requested to link researchers to PWID at hotspot sites. The selection of initial participants and their respective sites was based on information provided by 30 contacts at $\mathrm{MNH}$ methadone. At the hotspot site, the research assistant first introduced the study and those consented to join were recruited after signing a written consent. After completion of the interview and specimen collection, each participant was asked to refer other PWID to the study, continuously until the predetermined sample size was reached. A structured questionnaire was used to collect information related to social demographic characteristics, risk behavior, drug use habits and status of HIV, HBV and HCV (Additional file 1).

\section{Specimen collection}

Trained research assistants using plain vacutainer tubes drew about $4 \mathrm{ml}$ of venous blood from each participant aseptically, which were transported every day in cool boxes to the Muhimbili University of Health and Allied Sciences (MUHAS), Microbiology Laboratory for processing.

\section{Laboratory assays}

Blood was tested for HIV infection using SD Bioline HIV-1/2 3.0 (Standard Diagnostic, Seoul, Korea), and reactive samples were confirmed using Uni-GOLD HIV (Trinity Biotech, Wicklow, Ireland). HBsAg rapid test strip (Standard Diagnostic, Seoul, Korea) was used for the detection of hepatitis B surface antigen (HBsAg). The presence of $\mathrm{HCV}$ infection was determined by the detection of IgG antibodies to HCV using an anti-HCV rapid test strip (Standard Diagnostic, Seoul, Korea).

\section{Data analysis}

Data were entered in excel software and analysed using Statistical Package for Social Sciences (SPSS) version 20.0. Categorical variables were summarized as proportions while continuous variables were summarized as median with inter-quartile range. The seroprevalence of $\mathrm{HIV}, \mathrm{HCV}$, and HBsAg among PWID was expressed in percentages and comparisons between the groups were done using Chi-Square. Low income was defined as earning less or equal to 45 US dollars per month. Binary 
simple logistic regression was first performed, followed by a multivariable logistic regression model to determine factors independently associated with HIV, HBV or $\mathrm{HCV}$ infection. All variables with $p$-value $<0.2$ in simple binary regression were included in the multivariable model. Associations in the multivariable logistic model were presented as adjusted odds ratios (AOR) with 95\% confidence interval (CI). Interactions between independent variables were examined, and the Wald test was used to test the associations of the variables and interactions. The Hosmer-Lemeshow test was used to examine the overall fitness of the model. The level of significance was specified at 0.05 .

\section{Results}

\section{Participants' characteristics}

The study recruited a total of 219 PWID. Around 2\% of PWID were eligible but did not provide written consent. The median age of the participants was 39 years; [Interquartile range $35-43$ year] (Table 1 ). The majority were males (74.9\%), unmarried (60.7\%), had basic primary education (62.6\%) and $57.1 \%$ earned less or equal to 45 US dollars per month. Approximately $32.0 \%$ had a history of drug injection for more than 3 years, $79.9 \%$ were injecting drugs more than 3 times per day, while $47.5 \%$ were sharing needles. More than half (51.1\%) either never used or used condom irregularly in the last 6 months (Table 1). None of the participants knew status of infection with any of the three viruses before enrolment in the study.

\section{Prevalence of HIV, HBV, HCV, and co-infection}

The overall seroprevalence of HIV, HBV and $\mathrm{HCV}$ was $33.8 \%$ [27.8-40.5], 7.8\% [4.9-12.1] and 50.2\% [43.756.8 ], respectively. One hundred and fifty-one $(68.9 \%)$ of PWID had serologic evidence of at least one infection, 49 (22.4\%) had at least two infections, while one $(0.5 \%)$ had serologic evidence of all the three viruses (Table 2). Considering co-infection, $0.9 \%$ had HIV + HBV, 16\% had $\mathrm{HIV}+\mathrm{HCV}$ and $6.4 \%$ had HBV + HCV. Among participants with HBV infection, 82.4\% had also HCV (Table 2). There was no sex-stratified significant difference observed regarding the occurrence of $\mathrm{HIV}, \mathrm{HBV}$ and $\mathrm{HCV}$ infections.

\section{Factors associated with HIV, HCV and HBV infections}

Factors associated with the occurrence of HIV, HCV, and HBV are summarized in Table 3. HIV infection was significantly higher among those who were married, sharing needles and inconsistent users of condoms $(p<0.05)$, while $\mathrm{HCV}$ was associated with drug injection for more than 3 years, and lack or irregular use of condoms $(p<0.05)$. HBV was not associated with any of the risk factors evaluated $(p>$ 0.05) (Table 3).
Table 1 Socio-demographic and behavioral characteristics of 219 PWID in Dar-es-salaam

\begin{tabular}{|c|c|c|}
\hline Variables & Frequency (n) & Percentages (\%) \\
\hline \multicolumn{3}{|l|}{ Age group (yrs) } \\
\hline$<39$ & 105 & 47.9 \\
\hline$\geq 49$ & 114 & 52. 1 \\
\hline \multicolumn{3}{|l|}{ Sex } \\
\hline Male & 164 & 74.9 \\
\hline Female & 55 & 25.1 \\
\hline \multicolumn{3}{|l|}{ Marital status } \\
\hline Unmarried & 133 & 60.7 \\
\hline Married & 86 & 39.3 \\
\hline \multicolumn{3}{|l|}{ Education level } \\
\hline Low education & 137 & 62.6 \\
\hline High education & 82 & 37.4 \\
\hline \multicolumn{3}{|l|}{ Occupation } \\
\hline Unemployed & 102 & 46.6 \\
\hline Employed & 54 & 24.7 \\
\hline Business & 63 & 28.8 \\
\hline \multicolumn{3}{|c|}{ Monthly income (USD) } \\
\hline$\leq \$ 45$ & 125 & 57.1 \\
\hline$>\$ 45$ & 94 & 42.9 \\
\hline \multicolumn{3}{|c|}{ Duration of injection } \\
\hline$\leq 3$ years & 149 & 68.0 \\
\hline$>3$ years & 70 & 32.0 \\
\hline \multicolumn{3}{|c|}{ Frequency of injection per day (last 6 months) } \\
\hline$\leq 3$ times & 44 & 20.1 \\
\hline$>3$ times & 175 & 79.9 \\
\hline \multicolumn{3}{|c|}{ Needle sharing (last 6 months) } \\
\hline No & 115 & 52.5 \\
\hline Yes & 104 & 47.5 \\
\hline \multicolumn{3}{|c|}{ Use of condom (last 6 months) } \\
\hline Never/Irregular & 112 & 51.1 \\
\hline Always & 107 & 48.9 \\
\hline
\end{tabular}

Multivariable logistic regression model was performed to measure the adjusted relationship between independent variables and occurrence of HIV, HCV, and HBV. Marital status was the only factor independently associated with HIV infection (AOR 2.04, 95\%CI -1.10 - 3.79), while $\mathrm{HCV}$ infection was associated with drug usage for more than 3 years (AOR; 2.04, 95\% CI - 1.11- 3.74). PWID who used condom regularly decreased odds of getting HCV infection (AOR $=0.42,95 \% \mathrm{CI}-0.22-0.79)$ (Table 4).

Potential interactions between marital status and condom use on HIV status was checked. The assumption was that the effect of condom use on HIV status is somewhat dependent on marital status. The $p$-value for 
Table 2 Seroprevalence of HIV, HBV, HCV, and co-infections among 219 PWID in Dar-es-salaam, Tanzania

\begin{tabular}{llll}
\hline Infection & $\begin{array}{l}\text { Frequency } \\
\text { positive }\end{array}$ & Seropositive & $\begin{array}{l}95 \% \mathrm{Cl} \\
\text { of seropositive }\end{array}$ \\
\hline HIV Antibody & 74 & 33.8 & $27.8-40.5$ \\
HBV surface antigen & 17 & 7.8 & $4.9-12.1$ \\
HCV antibody & 110 & 50.2 & $43.7-56.8$ \\
HIV + HBV & 2 & 0.9 & $0.3-3.3$ \\
HIV + HCV & 35 & 16.0 & $11.7-21.4$ \\
HBV + HCV & 14 & 6.4 & $3.8-10.4$ \\
HIV + HCV + HBV & 1 & 0.5 & $0.1-2.5$ \\
Any infection & 151 & 68.9 & $62.5-74.7$ \\
\hline
\end{tabular}

interaction term was 0.67 which is far away from significance level and there was no much difference between the model with interaction term and the preliminary main effects model. Based on these observations we drooped the interaction term in the final model. The Hosmer-Lemeshow test result was $p=0.147$, which indicated the fitness of the overall model.

\section{Discussion}

Our study shows that over two-thirds of PWID in this study had serologic evidence of infection with at least one virus, while $22.4 \%$ having dual or triple multiple infections. About one-third of the participants were HIV positive, half had evidence of $\mathrm{HCV}$ infection and $8 \%$

Table 3 Proportion of HIV, HCV, and HBV seropositive in relation to participants' characteristics

\begin{tabular}{|c|c|c|c|c|c|c|}
\hline \multirow[t]{2}{*}{ Variables } & \multicolumn{2}{|l|}{ HIV } & \multicolumn{2}{|l|}{$\mathrm{HCV}$} & \multicolumn{2}{|l|}{ HBV } \\
\hline & Pos (\%) & $\overline{p \text {-value }}$ & Pos (\%) & $\overline{p \text {-value }}$ & Pos(\%) & $p$-value \\
\hline Age group (yrs) & & 0.89 & & 0.73 & & 0.15 \\
\hline$<39$ & 35(33.3) & & $54(51.4)$ & & $11(10.5)$ & \\
\hline$\geq 39$ & $39(34.2)$ & & $56(49.1)$ & & $6(5.3)$ & \\
\hline Sex & & 0.13 & & 0.26 & & 0.38 \\
\hline Male & $60(36.6)$ & & $86(52.4)$ & & $11(6.7)$ & \\
\hline Female & $14(25.5)$ & & $24(43.6)$ & & $6(10.9)$ & \\
\hline Marital status & & 0.01 & & 0.25 & & 0.39 \\
\hline Unmarried & $36(27.1)$ & & $63(47.4)$ & & $12(9.0)$ & \\
\hline Married & $38(44.2)$ & & $47(54.7)$ & & $5(5.8)$ & \\
\hline Education level & & 0.33 & & 0.74 & & 0.08 \\
\hline Low education & $43(31.4)$ & & $70(51.1)$ & & $14(10.2)$ & \\
\hline High education & $31(37.8)$ & & $40(48.8)$ & & $3(3.7)$ & \\
\hline Occupation & & 0.39 & & 0.58 & & 0.98 \\
\hline Unemployed & $37(36.3)$ & & $55(53.9)$ & & $11(10.8)$ & \\
\hline Employed & $20(37.0)$ & & $26(48.1)$ & & $6(11.1)$ & \\
\hline Business & $17(27.0)$ & & $29(46.0)$ & & $0(0.0)$ & \\
\hline Monthly income (USD) & & 0.17 & & 0.63 & & 0.51 \\
\hline$\leq \$ 45$ & $47(37.6)$ & & $61(48.8)$ & & $11(8.8)$ & \\
\hline$>\$ 45$ & $27(28.7)$ & & $49(52.1)$ & & $6(6.4)$ & \\
\hline Duration of injection & & 0.18 & & 0.01 & & 0.053 \\
\hline$\leq 3$ years & $46(30.9)$ & & $66(44.3)$ & & $8(5.4)$ & \\
\hline$>3$ years & $28(40.0)$ & & $44(62.9)$ & & $9(12.9)$ & \\
\hline Frequency of injection per day (last 6 months) & & 0.76 & & 0.48 & & 0.12 \\
\hline$\leq 3$ times & 14(31.8) & & $20(55.5)$ & & $6(13.6)$ & \\
\hline$>3$ times & $60(34.3)$ & & $90(51.4)$ & & $11(6.3)$ & \\
\hline Needle sharing (last 6 months) & & 0.03 & & 0.84 & & 0.59 \\
\hline No & $31(27.0)$ & & $57(49.6)$ & & $10(8.7)$ & \\
\hline Yes & $43(41.3)$ & & $53(51.0)$ & & $7(6.7)$ & \\
\hline Condom use (last 6 months) & & 0.02 & & 0.004 & & 0.39 \\
\hline Never/irregular & $46(41.1)$ & & $67(59.8)$ & & $7(6.2)$ & \\
\hline Always & $28(26.2)$ & & $43(40.2)$ & & $10(9.3)$ & \\
\hline
\end{tabular}


Table 4 Association of participants' characteristics with the adjusted odds of seropositive for HIV, HBV, and HCV among PWID in Dar-es-salaam

\begin{tabular}{|c|c|c|c|c|c|c|}
\hline \multirow[t]{2}{*}{ Variable } & \multicolumn{2}{|l|}{ HIV } & \multicolumn{2}{|l|}{$\mathrm{HCV}$} & \multicolumn{2}{|l|}{ HBV } \\
\hline & COR $(95 \% \mathrm{Cl})$ & AOR $(95 \% \mathrm{Cl})$ & COR $(95 \% \mathrm{Cl})$ & AOR $(95 \% \mathrm{Cl})$ & $\operatorname{COR}(95 \% \mathrm{Cl})$ & AOR $(95 \% \mathrm{Cl})$ \\
\hline Age $>39 y r s$ & $1.04(0.59-1.82)$ & $\mathrm{a}$ & $0.91(0.54-1.55)$ & $\mathrm{a}$ & $0.48(0.17-1.33)$ & $0.56(0.17-1.79)$ \\
\hline Male Sex (Ref. Female) & $0.59(0.29-1.74)$ & $0.62(0.29-1.30)$ & $0.70(0.38-1.29)$ & $0.93(0.48-1.88)$ & $1.70(0.60-4.84)$ & $1.51(0.42-5.39)$ \\
\hline Married Marital status (Ref. Unmarried) & $2.13(1.20-3.78)$ & $2.04(1.10-3.79)$ & $1.34(0.78-2.31)$ & $1.03(0.57-1.86)$ & $0.62(0.21-1.83)$ & $0.66(0.19-2.26)$ \\
\hline High education level (Ref. Low level) & $1.33(0.75-2.36)$ & a & $0.91(0.53-1.58)$ & a & $0.33(0.09-1.20)$ & $0.31(0.08-1.25)$ \\
\hline Employed (Ref: Unemployed) & $1.03(0.52-2.05$ & a & $0.79(0.41-1.54)$ & a & $1.04(0.36-2.97)$ & a \\
\hline Business (Ref: Unemployed) & $0.65(0.33-1.29)$ & a & $0.73(0.39-1.37)$ & a & b & a \\
\hline Monthly Income>45USD & $0.67(0.37-1.19)$ & $0.58(0.32-1.06)$ & $1.14(0.67-1.95)$ & a & $0.71(0.25-1.98)$ & a \\
\hline $\mathrm{IDU}>3$ years & $1.49(0.83-2.69)$ & $1.31(0.69-2.46)$ & $2.13(1.89-3.81)$ & $2.04(1.11-3.74)$ & $2.60(0.96-7.06$ & $2.42(0.72-8.12)$ \\
\hline Injection > 3 times per day & $1.12(0.55-2.27)$ & a & $1.27(0.65-2.47)$ & a & $0.43(0.15-1.22)$ & $0.72(0.19-2.72)$ \\
\hline Needle sharing & $1.91(1.08-3.37)$ & $1.75(0.92-3.29)$ & $1.06(0.62-1.79)$ & $0.76(0.41-1.39)$ & $0.76(0.27-2.07)$ & $0.70(0.21-2.35)$ \\
\hline Use of condom & $0.51(0.29-0.90)$ & $0.76(0.39-1.48)$ & $0.45(0.26-0.77)$ & $0.42(0.22-0.79)$ & $1.55(0.57-4.22)$ & $1.26(0.34-4.71)$ \\
\hline
\end{tabular}

Key: AOR Adjusted odds ratio, $\mathrm{Cl}$ Confidence interval, COR Crude odds ratio, Ref Reference

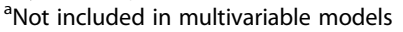

${ }^{b}$ Exncluded from multivariable medole because of zero observation in one cell

HBV infection. These findings are higher in comparison with latest systematic review of studies conducted in sub-Saharan Africa, showing estimates of $21.8 \%$ for HCV, $18.3 \%$ for HIV and 3.7\% for HBV [12]. Our findings are also higher compared with the previous report from Tanzania [6], possibly indicating an increase of infection with these three viruses among PWID. The rate of infections with these three viruses has shown a steady rise $[5,7,16]$. The findings indicate that PWID is a key population that needs urgent attention as a strategy to achieve control of HIV and viral hepatitis infections.

Alarmingly none of our study participants knew their status of infection with any of the three viruses before enrolment, which may indicate limited access to testing services. The higher prevalence of the three viruses among PWID compared to previous studies could be attributed, at least in part, due to a number of factors such low access to testing services and therefore not being able to access care and treatment services, multiple sexual partners and high frequency of partner change with low condom usage [6]. Indeed, regular condom use was associated with a $60 \%$ decreased odds of having $\mathrm{HCV}$ infection among those reported regular use of condom.

The association between condom use and HCV infection is interesting with the fact that $\mathrm{HCV}$ is not typically sexually transmitted. Previous studies have provided evidence that sexual transmission of $\mathrm{HCV}$ within low-risk heterosexual partnerships occurs at most with very low frequency [17]. However, in a population where there is a large pool of HCV infected persons like what our study found and sexual intercourse is common, even a low rate of sexual transmission can account for a large number of new cases. This may explain the decreased odds of $\mathrm{HCV}$ infection among those reported regular use of condom.

In the univariate analysis model, consistent condoms use showed a negative association with HIV infection, while marriage showed a positive association. However, in multivariable analysis condom use was not independently associated with HIV status. There was no evidence from the analysis to explain the absence of association of condom use and HIV infection in the adjusted analysis. The assumption that marriage could have an effect on the use of condom was not supported by the multivariable logistic regression model which included interaction term of marital status and condom use. Conversely, other previous studies have shown low condom usage among married couples $[8,16]$.

Our findings seem to indicate significant challenges in dealing with PWID that have certainly limited the impact of the initiatives undertaken by the Tanzania AIDS control program, including the outreach services. We recommend targeting PWID in their hideouts given illegality and stigma associated with drug use. The emphasis should be on social and psychological support, aiming at reducing high-risk behaviour, as well as increased access to HIV and viral hepatitis testing services and enrolment to antiretroviral and methadone schemes, which have shown clear benefits $[18,19]$. We did not observe a significant relationship between monthly income and needle sharing practice, supporting findings of previous studies conducted in Tanzania [14, $16,20]$, and disputing a common belief in the society that shared injection for drug use is due to financial constraints.

Our study may have several limitations. We acknowledge that reliance on self-reported information and 
dependency on the willingness of PWID to participate may have introduced selection and information biases and clustering of events and failure to recall. Reporting error may have occurred for some measures such as the frequency of injection and condom since this was based on participants' ability to recall events in the last 6 months. HBV vaccination status was not evaluated and therefore the risk of acquiring HBV infection cannot be determined. Finally, the snowball sampling approach employed in this study may have resulted in a biased sample that cannot be corrected by weighting schemes, limiting inferences of our findings.

\section{Conclusion}

The high prevalence of HIV, HBV, and HCV infections among PWID may hamper efforts to control these viruses in Tanzania. PWID should be actively screened at hotspots and linked to friendlier and more tailored care and treatment services for HIV, HBV, and HCV.

\section{Supplementary information}

Supplementary information accompanies this paper at https://doi.org/10. 1186/s12889-020-8294-8.

\section{Additional file 1. Interview questionnaire}

\section{Abbreviations}

$\mathrm{Cl}$ : Confidence interval; HBsAg: Hepatitis B surface antigen; HBV: Hepatitis B Virus; HCV: Hepatitis C Virus; HIV: Human immunodeficiency virus; IDU: Injecting drug use; MNH: Muhimbili National Hospital; MUHAS: Muhimbili University of Health and Allied Sciences; PWID: People who inject drugs

\section{Acknowledgments}

The authors are grateful to Muhimbili National Hospital in particular the Methadone Clinic for support, guidance, and corporation. Our sincere gratitude also goes to research assistants for their support in conducting the study and participants for agreeing to participate, which made this study possible.

\section{Authors' contributions}

RHK participated in conception, design, collection of data and drafting the manuscript. MIM participated in the design and overall coordination of the study. MVM and AAM contributed to the analysis and interpretation of data. MIM and MVM participated in critically revising the manuscript. All authors have read and approved the final manuscript.

\section{Funding}

The study did not receive support from any source of funding. The design of the study and collection, analysis, and interpretation of data and in writing the manuscript were the role of the authors only.

\section{Availability of data and materials}

All relevant data generated and analysed during this study are available from the corresponding author on reasonable request.

\section{Ethics approval and consent to participate}

The ethical approval for the study was obtained from the Senate Research and Publication Committee, the Institutional Review Board of Muhimbili University of Health and Allied Sciences. Written informed consent was obtained from each participant before enrolment. Each participant was provided with a description of the aim of the study, potential benefits and risks, blood collection procedures and assurance of confidentiality.
Participants who were found with any of screened pathogens were referred to the Muhimbili National hospital for further management. All clients' information and test results were confidentially kept.

\section{Consent for publication}

Not applicable.

\section{Competing interests}

The authors declare that they have no competing interests.

\section{Author details}

${ }^{1}$ Department of Microbiology and Immunology, Muhimbili University of Health and Allied Sciences, Dar es Salaam, Tanzania. ${ }^{2}$ Field Epidemiology and Laboratory Training Programme, Dar es Salaam, Tanzania.

Received: 25 February 2019 Accepted: 28 January 2020

\section{References}

1. NACP. HIV/AIDS and sexually transmitted infection suiveillance report 24, Tanzania Maninlans 2013-2014. 2014. www.nacp.go.tz/site/download/ NACP Report 24.pdf.

2. NBS. Tanzania HIV Impact Survey (THIS) 2016/17 summary sheet result. 2017 http://www.nbs.go.tz/nbs/takwimu/this2016-17/Tanzania_SummarySheet_ English.pdf.

3. Kilonzo SB, Gunda DW, Mpondo BCT, Bakshi FA, Jaka H. Hepatitis B virus infection in Tanzania: current status and challenges. J Trop Med. 2018;2018: 4239646.

4. Shao ER, Mboya IB, Gunda DW, Ruhangisa FG, Temu EM, Nkwama ML, et al. Seroprevalence of hepatitis $B$ virus infection and associated factors among healthcare workers in northern Tanzania. BMC Infect Dis. 2018;18(1):474

5. Bowring AL, Luhmann N, Pont S, Debaulieu C, Derozier S, Asouab F, et al. An urgent need to scale-up injecting drug harm reduction services in Tanzania: prevalence of blood-borne viruses among drug users in Temeke District, Dar-es-salaam, 2011. Int J Drug Policy. 2012;24(1):78-81.

6. Khatib A, Matiko E, Khalid F, Welty S, Ali A, Othman A, et al. HIV and hepatitis $B$ and $C$ co-infection among people who inject drugs in Zanzibar. BMC Public Health. 2017;17(1):917.

7. Mlunde LB, Sunguya BF, Mbwambo JK, Ubuguyu OS, Shibanuma A, Yasuoka J, et al. A mismatch between high-risk behaviors and screening of infectious diseases among people who inject drugs in Dar es Salaam, Tanzania. PLoS One. 2016;11(2):e0148598.

8. Williams ML, McCurdy SA, Atkinson JS, Kilonzo GP, Leshabari MT, Ross MW. Differences in HIV risk behaviors by gender in a sample of Tanzanian injection drug users. AIDS Behav. 2007;11(1):137-44.

9. Mathers BM, Degenhardt L, Phillips B, Wiessing L, Hickman M, Strathdee SA, et al. Global epidemiology of injecting drug use and HIV among people who inject drugs: a systematic review. Lancet. 2008;372(9651):1733-45.

10. Mumtaz GR, Weiss HA, Thomas SL, Riome S, Setayesh H, Riedner G, et al. HIV among people who inject drugs in the Middle East and North Africa: systematic review and data synthesis. PLoS Med. 2014;11(6):e1001663.

11. Nelson PK, Mathers BM, Cowie B, Hagan H, Des Jarlais D, Horyniak D, et al. Global epidemiology of hepatitis B and hepatitis $C$ in people who inject drugs: results of systematic reviews. Lancet. 2011;378(9791):571-83.

12. Degenhardt L, Peacock A, Colledge S, Leung J, Grebely J, Vickerman P, et al. Global prevalence of injecting drug use and sociodemographic characteristics and prevalence of HIV, HBV, and HCV in people who inject drugs: a multistage systematic review. Lancet Glob Health. 2017;5(12): e1192-e207.

13. Dewing SPA, Myers BJ, Parry CD. Review of injection drug use in six African countries: Egypt, Kenya, Mauritius, Nigeria, South Africa and Tanzania. Drugs: education, prevention and policy. Drugs. 2006;13(2):121-37.

14. McCurdy SA, Williams ML, Kilonzo GP, Ross MW, Leshabari MT. Heroin and HIV risk in Dar Es Salaam, Tanzania: youth hangouts, mageto and injecting practices. AIDS Care. 2005;17(Suppl 1):S65-76.

15. Ratliff EA, McCurdy SA, Mbwambo JK, Lambdin BH, Voets A, Pont S, et al. An overview of HIV prevention interventions for people who inject drugs in Tanzania. Adv Prev Med. 2013:2013:183187.

16. Tan AX, Kapiga S, Khoshnood K, Bruce RD. Epidemiology of drug use and HIV-related risk behaviors among people who inject drugs in Mwanza, Tanzania. PLoS One. 2015;10(12):e0145578. 
17. Terrault NA. Sex and hepatitis C. Am J Gastroenterol. 2005;100(4):825-6 [CommentEditorial].

18. Ksobiech K. Assessing and improving needle exchange programs: gaps and problems in the literature. Harm Reduct J. 2004;1 (1):4.

19. Rogers $\mathrm{SJ}$, Ruefli T. Does harm reduction programming make a difference in the lives of highly marginalized, at-risk drug users? Harm Reduct J. 2004;1(1):7.

20. Atkinson J, McCurdy S, Williams M, Mbwambo J, Kilonzo G. HIV risk behaviors, perceived severity of drug use problems, and prior treatment experience in a sample of young heroin injectors in Dar es Salaam, Tanzania. Afr J Drug Alcohol Stud. 2011;10(1):1-9.

\section{Publisher's Note}

Springer Nature remains neutral with regard to jurisdictional claims in published maps and institutional affiliations.

Ready to submit your research? Choose BMC and benefit from:

- fast, convenient online submission

- thorough peer review by experienced researchers in your field

- rapid publication on acceptance

- support for research data, including large and complex data types

- gold Open Access which fosters wider collaboration and increased citations

- maximum visibility for your research: over $100 \mathrm{M}$ website views per year

At $\mathrm{BMC}$, research is always in progress.

Learn more biomedcentral.com/submissions 